Review

\title{
Diabetes and its Potential Impact on Head and Neck Oncogenesis
}

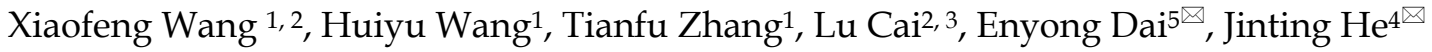 \\ 1. Department of Stomatology, China-Japan Union Hospital of Jilin University, Changchun 130033, Jilin Province, China \\ 2. Pediatric Research Institute, Department of Pediatrics, The University of Louisville School of Medicine, Louisville, KY 40292, USA \\ 3. Departments of Radiation Oncology, Pharmacology, and Toxicology, University of Louisville, Louisville, KY 40202, USA \\ 4. Department of Neurology, China-Japan Union Hospital of Jilin University, Changchun 130033, Jilin Province, China \\ 5. Department of Oncology and Hematology, China-Japan Union Hospital of Jilin University, Changchun 130033, Jilin Province, China \\ $\triangle$ Corresponding authors: Jinting He, E-mail: hejinting333@sina.com; Phone: 0086 431-84995114, Fax: 0086 431-84641026 and Enyong Dai, E-mail: \\ daienyong@yeah.net; Phone: 0086 431-84995595, Fax: 0086 431-84641026
}

(C) The author(s). This is an open access article distributed under the terms of the Creative Commons Attribution License (https://creativecommons.org/licenses/by/4.0/). See http://ivyspring.com/terms for full terms and conditions.

Received: 2019.04.09; Accepted: 2019.09.27; Published: 2020.01.01

\begin{abstract}
In recent years, the incidence of diabetes mellitus and cancer has increased sharply; indeed, these have become the two most important diseases threatening health and survival. Head and neck (HN) tumors are the sixth most common malignancies in humans. Numerous studies have shown that there are many common risk factors for diabetes mellitus and $\mathrm{HN}$ squamous cell carcinoma, including advanced age, poor diet and lifestyle, and environmental factors. However, the mechanism linking the two diseases has not been identified. A number of studies have shown that diabetes affects the development, metastasis, and prognosis of $\mathrm{HN}$ cancer, potentially through the associated hyperglycemia, hyperinsulinemia and insulin resistance, or chronic inflammation. More recent studies show that metformin, the first-line drug for the treatment of type 2 diabetes, can significantly reduce the risk of $\mathrm{HN}$ tumor development and reduce mortality in diabetic patients. Here, we review recent progress in the study of the relationship between diabetes mellitus and HN carcinogenesis, and its potential mechanisms, in order to provide a scientific basis for the early diagnosis and effective treatment of these diseases.
\end{abstract}

Key words: hyperglycemia, insulin resistance, hyperinsulinemia, chronic inflammation, immune system dysfunction, metformin

\section{Introduction}

"Head and neck" (HN) tumors include any tumor occurring in the oral cavity, oropharynx, hypopharynx, larynx, and esophagus. More than $90 \%$ of these are squamous cell carcinomas (SCCs) [1]. HN neoplasia is a common disease that seriously threatens human health, with 550,000 new cases and 300,000 deaths being reported annually worldwide during the past 30 years [2]. Furthermore, in 2019 it was estimated that there were 53,000 new cases of oral cavity or pharyngeal tumor and 10,860 deaths from these annually in the USA alone [3]. Oral malignant tumor is the most common malignant tumor of the head and neck, and $>90 \%$ of these are SCCs, such that its incidence is ranked sixth among all the malignant tumors [4].

Diabetes mellitus (DM) is a group of metabolic diseases characterized by hyperglycemia and caused by insufficient insulin secretion and/or defective insulin action [5]. In developed countries, the prevalence of diabetes has reached $3-7 \%$, and it has become the fifth leading cause of death worldwide, next only to cancer, acquired immune deficiency syndrome, and cardiovascular disease [6-10]. A previous report shows that the number of diabetic patients worldwide reached 382 million in 2014; this number is expected to reach 592 million by 2035 [11].

Type 1 diabetes was previously termed "insulindependent $\mathrm{DM}^{\prime}$ or "juvenile DM". Type 2 diabetes 
mellitus (T2DM), previously termed "non-insulindependent $\mathrm{DM}^{\prime \prime}$, is characterized by insulin resistance, which implies that target cells are unable to respond appropriately to insulin, and this form of the disease accounts for more than $90 \%$ of DM cases [12]. A substantial amount of epidemiological evidence indicates that diabetes not only increases the risk of many types of cancers, but also affects the long-term efficacy of cancer treatment. As early as 1932, Wilson [13] noticed that patients with T2DM may be at greater risk of tumor development. In recent years, a large number of studies have shown that diabetes significantly increases the incidence of malignant tumors and affects therapeutic efficacy [14]. It has been reported that diabetes is more common in patients with breast cancer, colorectal cancer, uterine cancer, liver cancer, and pancreatic cancer [15-24]. However, there is little or no information about how diabetes impacts $\mathrm{HN}$ and particular oral cancers. Here, we review available related studies and identify certain links between diabetes and HN cancers. We conclude that when diagnosing diabetes, additional attention should be paid to the possibility of co-existing malignant tumors. Emerging evidence indicates that metformin prevents not only diabetic cardiovascular complications, but also reduces tumor incidence and progression.

\section{DM and $\mathrm{HN}$ tumors}

Maynard and Pearson first identified a link between DM and tumorigenesis in 1909 [25]. Epidemiologic studies have since shown that diabetic patients are at greater risk of colon cancer, endometrial cancer, breast cancer, and others [26-28]. This phenomenon is particularly evident with respect to colon cancer, with clinical studies having shown that the risk of colon cancer in diabetic patients is 1.33.0 times higher [28-30]. As a consequence, the American Oncology Association and the American Diabetes Association issued a statement regarding the possible links between cancer and diabetes (principally T2DM), which was divided these into three categories: (a) unmodifiable risk factors (age, sex, and ethnicity), (b) modifiable risk factors (including obesity, physical activity, smoking, and alcohol consumption), and (c) biological links between diabetes and cancer (for example, hyperinsulinemia, hyperglycemia, insulin resistance, and chronic inflammation) [31].

There are many common risk factors for DM and HNSCC, including advanced age, poor diet and lifestyle, and environmental factors [32]. In Asia, Tseng found a higher risk of HN cancer in individuals with DM than in those without [33], and a retrospective study of patients with oral SCC $(n=600)$ and controls $(n=574)$ found that there was a higher prevalence of DM in the former $(24.3 \%$ versus $11.1 \%)$ [34]. Recently, it has been shown that the overall survival, relapse-free survival, and tumor-specific survival of patients with oral SCC and DM are lower than in patients without DM, and the general prognosis is also poorer [35]. An estimated 30.3 million people of all ages (or $9.4 \%$ of the U.S. population) had diabetes in 2015[36]. Furthermore, Bányai et al. demonstrated a correlation between oral cancer and metabolic disorders (DM and fasting hyperglycemia) in Hungary, with the number of people having these defects being much larger among patients with oral SCC than among controls [37]. Bao et al. examined data from 25,154 twins born until 1958 in the Swedish Twin Registry to determine whether diabetes in middle age affects the risk of cancer in later life, and whether genetic and early-life environmental factors might play a role in any association, and found that DM does indeed increase the risk of pharyngeal cancer in later life [38]. Another study suggested that patients with DM are at significantly greater risk of thyroid cancer than non-diabetic individuals, although, whereas there was a strong positive association in women, it was not significant in men [39]. Liu et al. found that long-term exposure to high glucose concentrations predisposes to the development of malignant tumors in vitro and in vivo. Compared with non-diabetic patients with $\mathrm{HN}$ tumors, those with DM had a lower survival rate, suggesting that diabetic pathophysiology may have a significant influence on HN SCC metastasis. [40]. In addition, a number of epidemiologic studies have shown that DM increases the risk of oral tumors and precancerous lesions, such as leukoplakia, erythema, and lichen planus [34,41-43]. By contrast, Stott-Miller et al. found a weak negative correlation between DM and HNSCC (odds ratio, 0.92; 95\% confidence interval, 0.88-0.96), although this is not consistent with the majority of research findings [44]. Hence, we first summarize the link between $\mathrm{DM}$ and $\mathrm{HN}$ tumorigenesis (a brief overview is presented in Table $1)$.

Western and Asian diets contain different nutrients, which may have different effects on development of diabetes. In the U.S., Ankola et al [45] confirmed that from 2002 to 2011, HNSCC patients at Montefiore Medical Center in the Bronx (NY) comprised those with primary oropharyngeal $(36 \%)$, laryngeal $(33 \%)$, and oral cavity cancers $(31 \%)$. In Japan, Nishimura et al [46] examined $107 \mathrm{HN}$ cancer patients from January 2004 to August 2005 and found that the incidence of end-stage renal disease is 1.3 times higher in the United States than in Japan. In Taiwan, Tseng found that the incidence of HNC in 
patients newly diagnosed with DM was 1.47 times higher than that in a control group [33].

Table 1. Link between diabetes mellitus and head and neck tumorigenesis

\begin{tabular}{|c|c|c|}
\hline Cancer type & Findings & Reference \\
\hline $\begin{array}{l}\text { Head and neck } \\
\text { squamous cell } \\
\text { carcinoma } \\
\text { (HNSCC) }\end{array}$ & $\begin{array}{l}\text { Incidence of oral cavity cancer, } \\
\text { oropharyngeal cancer, and nasopharyngeal } \\
\text { carcinoma were significantly higher in } \\
\text { patients with DM aged } 40 \text { to } 65 \text { years. }\end{array}$ & 32 \\
\hline $\begin{array}{l}\text { Head and neck } \\
\text { squamous cell } \\
\text { carcinoma } \\
\text { (HNSCC) }\end{array}$ & $\begin{array}{l}\text { Long-term exposure to high glucose } \\
\text { concentrations predisposes to the } \\
\text { development of malignant tumors in vitro } \\
\text { and in vivo. }\end{array}$ & 40 \\
\hline Pharyngeal cancer & $\begin{array}{l}\text { DM does indeed increase the risk of } \\
\text { pharyngeal cancer in later life }\end{array}$ & 38 \\
\hline Thyroid cancer & $\begin{array}{l}\text { Women patients with DM are at } \\
\text { significantly greater risk of thyroid cancer } \\
\text { than non-diabetic individuals. }\end{array}$ & 39 \\
\hline $\begin{array}{l}\text { Oral tumors and } \\
\text { precancerous } \\
\text { lesions }\end{array}$ & $\begin{array}{l}\text { DM increases the risk of oral tumors and } \\
\text { precancerous lesions, such as leukoplakia, } \\
\text { erythema, and lichen planus. }\end{array}$ & $33,41-43$ \\
\hline $\begin{array}{l}\text { Oral squamous cell } \\
\text { carcinoma (OSCC) }\end{array}$ & $\begin{array}{l}\text { OSCC Patients with DM had a significant } \\
\text { increase in mortality and recurrence } \\
\text { compared with those without DM. }\end{array}$ & 34 \\
\hline
\end{tabular}

Although many studies have demonstrated a relationship between $\mathrm{DM}$ and $\mathrm{HN}$ tumors, the mechanisms responsible for this link are not yet understood. DM may affect the development, metastasis, and/or prognosis of $\mathrm{HN}$ cancer through the effects of hyperglycemia, hyperinsulinemia, insulin resistance, chronic inflammation, and/or microvascular disease, which may be negatively correlated with the prognosis of the tumor [34,35,47]. Furthermore, anti-hyperglycemic drugs with differing mechanisms of action may have differential effects on oral SCC. Therefore, we next review the effects of DM and anti-hyperglycemic drugs on oral SCC and the potential mechanisms involved.

\section{Potential mechanisms whereby DM influences $\mathrm{HN}$ tumors}

Tumor formation is a complex process, but it can be divided into initiation, promotion, and progression phases, and various factors can influence each[48]. When the complexity of the pathogenesis of DM is added, it becomes clearer why the relationship between DM and cancer has yet to be fully explained [49]. However, DM may affect the development of oral tumors through the influence of pathologic features, including hyperglycemia, hyperinsulinemia, insulin resistance, chronic inflammation, and immune system dysfunction.

\section{Hyperglycemia}

It is well known that cancer cells show more rapid glucose uptake and metabolism, i.e. increased expression of glucose transporter 1 (GLUT-1) and
HK-II, than normal cells; these characteristics enable rapid growth and division[50]. Hyperglycemia and hyperlipidemia are the main pathologic features of the metabolic disorders that comprise DM, and hyperglycemia implies the availability of an of the most important metabolic substrate for tumor cells [51]. Hyperglycemia promotes cellular proliferation by increasing expression of GLUT-1, GLUT-3, protein kinase $C$, peroxisome proliferator-activated receptor alpha/gamma and epithelial growth factor [52]. In vitro experiments have shown that high glucose concentrations damage non-tumor cells and lead to many diabetic complications [53]. By contrast, most cancer cells are highly dependent on glucose and persistently high glucose concentrations can promote the growth of cancer cells [54]. Furthermore, a previous study found that hyperglycemia is a risk factor for gingival cancer, which may be due to a reduction in the bactericidal activity of immune cells in a high glucose environment, increasing susceptibility to bacterial infection [55]. IGF-1 is expressed by oral SCCs [56]; therefore, there may be a risk that hyperglycemia increases proliferation of oral SCC cells.

However, hyperglycemia is not only able to stimulate proliferation of cancer cells; it can also induce tumor resistance to chemotherapy. For instance, persistent high glucose concentrations protect HN SCCs by reducing the cytotoxic effect of cisplatin, which may be the result of higher expression of the $A b c g 2$ gene, a mediator of drug resistance [57].

\section{Hyperglycemia and obesity}

With the improvement in living standards, the associated consumption of high-energy diets has increased the prevalence of obesity. Obesity is associated with a greater risk of cardiovascular and cerebrovascular disease, and there is evidence that obesity is also a risk factor for malignancy. Previous studies suggest that the high incidence of malignant tumors in obese patients is related to the associated reduction in adiponectin secretion, the increase in leptin secretion, and the higher insulin-like growth factor (IGF) expression. Recent studies have elucidated the relationship between obesity and malignancy from a number of perspectives. Obesity results in tissue hypoxia, expression of tumor-susceptibility genes, and a higher rate of differentiation of adipose stromal cells, which promote the transformation of normal cells into malignant tumors [58]. Hyperlipidemia is a risk factor for oral cancer [33]. In addition, obese and diabetic Tsumura Suzuki Obese Diabetic mice are susceptible to 4-nitroquinoline 1-oxide-induced esophageal 
carcinogenesis, suggesting that obesity and DM are risk factors for esophageal SCC [32]. Dysregulation of 72 lipid metabolites has been demonstrated in oral SCC, and a combination of TGFB1 (transforming growth factor- $\beta 1$ ), SPP1 (secreted phosphoprotein-1), and SERPINNE1 (Serine protease-1) is useful for predicting oral SCC prognosis [59].

\section{Insulin resistance, hyperinsulinemia, and IGFs}

Hyperinsulinemia, which develops secondary to insulin resistance, plays an important role in the development of malignant tumors. When target cells fail to respond effectively to normal insulin concentrations, pancreatic insulin secretion increases in compensation, leading to hyperinsulinemia, which can affect cell proliferation and metabolism, and promote tumor formation. Indeed, it has been reported that insulin resistance and hyperinsulinemia directly promote carcinogenesis in DM patients $[60,61]$. A previous meta-analysis shows that hyperinsulinemia is a risk factor for multiple malignant tumors [62].

Furthermore, not only insulin itself, but also the insulin receptor, IGF receptor, and IGF, play roles in tumorigenesis. Oxidative stress is a key mechanism of insulin resistance, with large quantities of superoxide anions being produced in mitochondria, which inactivate insulin receptors and are carcinogenic [63]. Insulin can increase the concentration of free, biologically active IGF-1 in the circulation by inhibiting the synthesis of IGF-binding protein in the liver [64]. Human cancer cells generally express both the insulin receptor and the IGF-1 receptor [65]. Activation of insulin receptors can induce mitosis [66], so it may be that insulin can promote the development and progression of $\mathrm{HN}$ tumors, but insulin may also have an indirect tumorigenic effect through IGF-1 [67]. Indeed, IGF-1 has been shown to be a more potent promoter of cell mitosis and inhibitor of apoptosis than insulin [68]. Consequently, a high concentration of IGF-1 suppresses apoptosis and induces cell cycle progression, angiogenesis, and metastatic activity in various cancers [69]. Meanwhile, studies have shown that insulin receptors and IGF receptors are highly expressed in many tumors $[49,70,71]$. IGF-1, acting through its receptors, also promotes neovascularization by inducing vascular endothelial growth factor gene transcription, which promotes tumor development [72]. Binding of insulin or IGF-1 to their receptors activates many signaling pathways, which can promote the proliferation, invasion, and metastasis of cancer cells, inhibit apoptosis, and lead to the development and progression of many types of cancer cell [73]. In particular, binding of either ligand to a receptor activates the phosphoinositol 3-kinase/Akt/ mechanistic target of rapamycin (mTOR) pathway, leading to abnormal cell proliferation, inhibition of apoptosis, and carcinogenesis [74]. Importantly, IGF-1 is expressed in oral SCCs [56].

\section{Chronic inflammation}

Pro-inflammatory cytokines, such as interleukin (IL)-1, IL-6, and tumor necrosis factor alpha (TNF-alpha), can cause abnormal serine phosphorylation of insulin receptor substrates through multiple pathways, which inhibits normal tyrosine phosphorylation, thereby interfering with insulin signal transmission and inducing insulin resistance [75]. Fewer tumor suppressor and larger numbers of pro-inflammatory cells are found in oral and esophageal tumors [76-78]. Furthermore, the infiltration of inflammatory cells can increase the risk of cancer by secreting bioactive molecules, such as cytokines and chemokines [79]. In addition, the production of anti-inflammatory cytokines is impaired, complement-mediated phagocytosis is inhibited, and chemotactic phagocytosis by monocytes/macrophages is impaired in DM patients [80], leading to a higher probability of infection. Consistent with this, epidemiologic studies have shown that cancer is often associated with chronic inflammatory disease and infection. Inflammation can play a role in various stages of cancer development through a number of mechanisms [81]. Hyperglycemia-induced chronic inflammation is very common in the tissues of diabetic patients, and in particular, T2DM is associated with a variety of oral inflammatory diseases $[82,83]$. Furthermore, there is evidence [84-87] that persistent inflammation increases genetic instability and cancer risk. Chronic inflammation is associated with a high concentration of TNF-alpha, which activates the mitogen-activated protein kinase (MAPK) and nuclear factor-kappa B (NF-kB) signaling pathways. NF-KB not only promotes the proliferation of malignant cells and inhibits apoptosis, thereby improving their survival rate, but also promotes angiogenesis and metastasis. In these ways, it can mediate the responses of cells to hormones and chemotherapeutic drugs [84,88]. Various chronic inflammatory diseases have been shown to accelerate carcinogenesis. Atrophic stomatitis and the metabolic and immunologic changes in DM lead to cellular transformation and promote the development of precancerous lesions, such as leukoplakia. Candida infection is highly prevalent in DM patients, and can induce squamous epithelial metaplasia and epithelial cell proliferation [89]. Finally, a recent study that investigated the effects of DM on the activation of signal transduction 
pathways in oral cancer found that DM accelerates cellular proliferation by activating the Ras/Raf/ MAPK signal transduction pathway [90].

Diabetic patients are susceptible to infection because high blood sugar levels promote survival of bacteria. An etiological study of HNSCC found that human papillomavirus (HPV) infection was significantly associated with occurrence and development of HN tumors [91]. More and more studies show that high-risk HPV 16/18 subtype infection is another key independent pathogenic factor for HNSCC (after smoking and drinking), especially in those with oropharyngeal cancer [92]. In HNSCC, HPV mainly infects basal epithelial cells and mucosal cells. HPV integrates ribonucleic acid into host cells and induces deletion of E2 gene fragment. The E2 gene negatively regulates HPV-E6/HPV-E7 oncogenes [93]. In cases where E2 deletion leads to increased expression of HPV-E6/HPV-E7 genes, the expressed proteins can bind and degrade P53 and $\mathrm{pRb}$, respectively, meaning that infection is not detrimental to the host. Dysregulation of the cell cycle leads to infinite proliferation and malignant transformation of host cells [94]. Surviladze et al. [95] showed that HPV 16 virus inhibits autophagy in host cells via the $\mathrm{P} 13 \mathrm{~K} / \mathrm{mTOR}$ signaling pathway, thereby affecting the cell cycle.

\section{Immunologic system}

Cellular immunity, humoral immunity, and cytokines all play a role in anti-tumor immunity, but cellular immunity is the most significant. Their poor immune function and hyperglycemia make diabetic patients more susceptible to infection and make such infections more difficult to control. Cellular immune dysregulation reduces anti-tumor immunity [96-98]. For example, hyperglycemia affects the function of B lymphocytes, which produce antibodies in response to antigen stimulation, and low levels of immunoglobulin (Ig)M, IgA, and IgG indicate humoral immune deficiency [99]. T lymphocytes are classified into cluster of differentiation (CD)8+ and CD4+ subgroups, but CD3+ cells are mature $\mathrm{T}$ lymphocytes, meaning that a reduction in peripheral CD3+ cell numbers is consistent with a higher degree of T lymphocyte immaturity $[100,101]$. Such immune deficiency increases susceptibility to infection $[102,103]$. However, the immune surveillance systems of the body cannot detect transformed tumor cells, permitting the development of malignant tumors.

Oral lichen planus (OLP) is a precancerous lesion, and the relationship between DM and OLP has been the subject of significant research. It has been suggested that the endocrine dysfunction in DM and the related immunodeficiency may contribute to the development of OLP [43]. Epidemiologic studies have supported links between DM and oral precancerous lesions, such as mucosal leukoplakia [41], erythema [42], and lichen planus [43]. These may be mediated by immune deficiency, secondary to endocrine dysfunction, which accelerates the development of such lesions.

\section{Effect of metformin and other diabetic drugs on $\mathrm{HN}$ tumors}

Metformin is a biguanide drug that inhibits hepatic gluconeogenesis and increases tissue insulin sensitivity, thereby having an anti-hyperglycemic effect [104]. It is well tolerated, and its pharmacokinetics are well characterized [104,105]. It was originally extracted from Syringa franca and is now used as the first-line drug for the treatment of T2DM, especially in the presence of obesity [106]. Interestingly, there is growing evidence that metformin also has antineoplastic effects. Its use is associated with a significant reduction in the risk of cancer and improvements in the survival of diabetic patients with medullary thyroid carcinoma [107], esophageal cancer [108], lung cancer [109], liver cancer [110], gastric cancer [111,112], pancreatic cancer [113,114], colorectal cancer [115], prostate cancer [116,117], ovarian cancer [118], endometrial cancer [119], and breast cancer [120].

There has also been significant research into the potential of metformin for the prevention and treatment of $\mathrm{HN}$ cancer, which is summarized in Table 2. Rêgo et al. systematically reviewed the effects of metformin in patients with HN SCC before 2014, finding that metformin reduces the local recurrence and metastasis of such tumors, and improves overall survival and disease-free survival [121]. Skinner et al. found that patients treated with metformin had a significantly lower incidence of local recurrence after radiotherapy for HN SCC: their overall 5 year survival was 2.1 times that of patients not treated with metformin. However, the report did not indicate whether these patients had DM [122]. Yen et al. studied the risk of HN SCC in 66,600 diabetic patients in Taiwan, and found that the incidence of HN SCC was 0.34 times lower when metformin was being administered than when it was not, although the benefit was clearest for patients over 40 years of age[123]. In 2014, Becker et al. found no significant difference in the risk of HN SCC between patients taking metformin and those who were not, but also found that long-term use of metformin reduced the risk of laryngeal cancer[124]. Kwon et al. found that diabetic patients with HN SCC who were not using metformin demonstrated a higher incidence of recurrence than non-diabetic patients[125]. And in 
2016, Figueiredo et al. found that diabetic patients had a lower risk of HN SCC than non-diabetic patients. Therefore, it was suggested that the reason why the presence of DM is associated with a lower risk of $\mathrm{HN}$ SCC might be due to the use of metformin[126].

Table 2. Published studies regarding the effects of metformin on head and neck tumors

\begin{tabular}{|c|c|c|}
\hline Year & $\begin{array}{l}\text { Author } \\
\text { (Ref.) }\end{array}$ & Principal Findings \\
\hline 2012 & $\begin{array}{l}\text { Skinner et } \\
\text { al. (122) }\end{array}$ & $\begin{array}{l}\text { Metformin reduces the incidence of local recurrence after } \\
\text { radiotherapy. }\end{array}$ \\
\hline 2012 & $\begin{array}{l}\text { Vitale et al. } \\
\text { (127) }\end{array}$ & $\begin{array}{l}\text { Metformin prevents development of tongue tumors } \\
\text { induced by } 4 \text {-nitroquinoline } 1 \text {-oxide. }\end{array}$ \\
\hline 2013 & $\begin{array}{l}\text { Patel et al. } \\
\text { (128) }\end{array}$ & $\begin{array}{l}\text { Metformin inhibits the activity of OCT-3-expressing head } \\
\text { and neck squamous cell carcinomas. }\end{array}$ \\
\hline 2014 & $\begin{array}{l}\text { Yen et al. } \\
(123)\end{array}$ & $\begin{array}{l}\text { The incidence of head and neck squamous cell carcinoma } \\
\text { was lower when metformin was used in patients over } 40 \\
\text { years old than when metformin was not used. }\end{array}$ \\
\hline 2014 & $\begin{array}{l}\text { Becker et } \\
\text { al. }(124)\end{array}$ & $\begin{array}{l}\text { Long-term use of metformin reduces the risk of laryngeal } \\
\text { cancer. }\end{array}$ \\
\hline 2015 & $\begin{array}{l}\text { Rêgo et } \\
\text { al.(121) }\end{array}$ & $\begin{array}{l}\text { Metformin reduces the local recurrence and metastasis of } \\
\text { head and neck squamous cell carcinoma. }\end{array}$ \\
\hline 2015 & $\begin{array}{l}\text { Kwon et al. } \\
(125)\end{array}$ & $\begin{array}{l}\text { Diabetic patients with head and neck squamous cell } \\
\text { carcinoma who did not use metformin had a higher } \\
\text { incidence of recurrence than non-diabetic patients. }\end{array}$ \\
\hline 2015 & $\begin{array}{l}\text { Madera et } \\
\text { al. (129) }\end{array}$ & $\begin{array}{l}\text { Metformin prevents tumor growth in HNSCC cells } \\
\text { oncogenes expressing OCT-3 driven by mutant PIK3CA } \\
\text { and HPV inhibiting mTOR signal. }\end{array}$ \\
\hline 2016 & $\begin{array}{l}\text { Figueiredo } \\
\text { et al. (126) }\end{array}$ & $\begin{array}{l}\text { People with diabetes have a lower risk of HNC than } \\
\text { those without diabetes; metformin use may explain this } \\
\text { inverse association. }\end{array}$ \\
\hline 2018 & $\begin{array}{l}\text { Stokes et } \\
\text { al. }(130)\end{array}$ & $\begin{array}{l}\text { Metformin improves the cancer-specific survival rate in } \\
\text { patients with head and neck cancer and diabetes } \\
\text { mellitus. }\end{array}$ \\
\hline 2019 & $\begin{array}{l}\text { Ping Wu et } \\
\text { al. (131) }\end{array}$ & $\begin{array}{l}\text { Metformin suppresses FaDu cell proliferation by } \\
\text { reducing SNHG7 expression via SAHH-mediated DNA } \\
\text { methylation. }\end{array}$ \\
\hline 2019 & $\begin{array}{l}\text { Kuo et al. } \\
(132)\end{array}$ & $\begin{array}{l}\text { Metformin inhibits the proliferation of non-stem HN } \\
\text { SCC cells, but causes a dose-dependent induction of the } \\
\text { stem cell genes CD } 44 \text {, BMI-1, and OCT- } 4 \text { to protect SCCs } \\
\text { against cisplatin in vitro. }\end{array}$ \\
\hline
\end{tabular}

OCT-3: octamer-binding transcription factor 3; OCT-4: octamer-binding transcription factor 4; PIK3CA: phosphatidylinositol-3-kinase catalytic subunit alpha; HPV: human papillomavirus; CD44: cluster of differentiation 44; BMI-1:

B-lymphoma Moloney murine leukemia virus insertion region-1.

To investigate this possibility, Vitale et al. used the carcinogen 4-nitroquinoline 1-oxide to induce tongue cancer in mice, and found that metformin prevented development of this form of HNSCC[127]. Patel et al. found that OCT-3 (octamer-binding transcription factor 3 ) is not expressed in normal oral cells, but is expressed in HN SCCs. Metformin inhibited high expression of OCT-3 in HN SCCs, but had little effect on low levels of expression. When expression or activity of OCT-3 was blocked, metformin could not induce AMP-activated protein kinase (AMPK) activation and inhibit mTORC1[128]. Madera et al. reached similar conclusions[129]. A retrospective study published by Stokes et al. [130] in 2018 found that, HN cancers patients with DM improved greatly after taking metformin. These results suggest that metformin can improve the cancer-specific survival rate in patients with both $\mathrm{HN}$ cancer and DM. In addition, another recent study demonstrated that metformin suppresses proliferation of human SCC FaDu cells by reducing SNHG7( small nucleolar RNA host gene 7) expression via SAHH-mediated DNA methylation [131]. Kuo et al. suggested that metformin inhibits proliferation of non-stem HN SCC cells, but that it also causes a dose-dependent induction of the stem cell genes CD44(cluster of differentiation 44), BMI-1( B-lymphoma Moloney murine leukemia virus insertion region-1), and OCT-4(octamer-binding transcription factor 4) to protect SCCs against the effect of cisplatin in vitro [132].

Some epidemiological studies show that sulfonylureas increase the risk of cancer in those with T2DM. One possible mechanism is based on the fact that individuals with T2DM are insulin-resistant; sulfonylureas promote insulin secretion, thereby increase circulating insulin levels even further [133]. A Meta-analysis by Thakar et al. [134] on the relationship between use of metformin and sulfonylureas and the risk of tumorigenesis in T2DM patients showed that metformin reduced the risk of tumorigenesis whereas sulfonylureas may increase the risk of tumorigenesis. In addition, based on adverse events reported by FDA (Food and Drug Administration of the United States) analysis data, use of the GLP-1 receptor agonist exenatide and the DPP-4 inhibitor statin has been questioned [135]; these two drugs may increase the risk of malignant tumors, especially thyroid cancer and pancreatic cancer.

Although numerous studies of the anti-tumor effects of metformin and other diabetic drugs have been conducted, the mechanism involved remains unclear. Insulin resistance and hyperinsulinemia can directly promote carcinogenesis in diabetic patients, and metformin reduces cancer risk by ameliorating insulin resistance, hyperglycemia, and hyperinsulinemia [60, 61]. However, other anti-diabetic drugs, such as pioglitazone, also ameliorate insulin resistance but do not have significant effects on cancer [47]. Therefore, metformin may have a specific additional anti-cancer property [47]. The mechanisms involved in the anti-tumor effect of metformin may include activation of the AMPK pathway [136-139], the induction of cell cycle arrest $[140,141]$, the promotion of cell apoptosis $[136,142]$, the inhibition of the invasion and metastasis of cancer cells $[143,144]$, and the killing of cancer stem cells [143].

\section{Conclusions and perspectives}

Both DM and malignant tumors are highly prevalent, and their incidences are increasing year by year [145]. They are therefore both major diseases 
threatening human health, but there are numerous and varied uncontrollable risk factors for each, and differences in the research populations, sample sizes, and statistical methods used in different studies complicate their identification. Thus, whether DM is a risk factor for $\mathrm{HN}$ tumors or affects their prognosis remains uncertain. Many studies have shown that there is a relationship between the two diseases, but the mechanism involved is clearly complex and requires further elucidation. Recent studies have shown that DM may be associated with higher malignancy of HN tumors, through hyperglycemia, insulin resistance, chronic inflammation, and/or immune deficiency, which can seriously affect the quality of life of patients with $\mathrm{HN}$ tumors. Furthermore, although DM is easily diagnosed, the diagnosis of malignant tumors often requires the use of invasive diagnostic procedures. Nevertheless, it seems clear that diabetic patients have a higher risk of malignant tumors than the general population, implying that, when diagnosing diabetes, attention should be paid to the possibility of malignant tumors also being present. Furthermore, the use of metformin as the first-line medication for T2DM is also associated with an anti-tumor effect. We believe that further research may support the production of a new generation of anti-cancer drugs based upon metformin.

\section{Acknowledgements}

This study was funded by a grant from the Bethune Project of Jilin University of China (grant no. 2018B02), the Project of Health and Family Planning Commission of Jilin Province (grant no. 2017F007), and the National Natural Science Foundation of China (grant no.81903881).

The personnel expenses and partial research-related expenses for Dr. Xiaofeng Wang was provided by Jilin University through a collaborative research agreement between the University of Louisville and Jilin University, Changchun, China.

\section{Competing Interests}

The authors have declared that no competing interest exists.

\section{References}

1. Gao J, Panizza B, Johnson NW, et al. Basic consideration of research strategies for head and neck cancer. Front Med. 2012; 6:339-53.

2. Saba NF, Goodman M, Ward K, et al. Gender and ethnic disparities in incidence and survival of squamous cell carcinoma of the oral tongue, base of tongue, and tonsils: a surveillance, epidemiology and end results program-based analysis. Oncology. 2011; 81:12-20.

3. Siegel RL, Miller KD, Jemal A. Cancer statistics, 2019 [J]. CA Cancer J Clin. 2019; 69: 7-34.

4. Warnakulasuriya S. Global epidemiology of oral and oropharyngeal cancer. Oral Oncol. 2009; 45: 309.

5. Hegazi R, El-Gamal M, Abdel-Hady N, et al. Epidemiology of and risk factors for type 2 diabetes in Egypt. Ann Glob Health. 2015; 81:814-20.
6. Li L, Sheng X, Zhao S H, et al. Nanoparticle-encapsulated emodin decreases diabetic neuropathic pain probably via a mechanism involving P2X3 receptor in the dorsal root ganglia. Purinergic Signal. 2017; 13: 559-68.

7. Malecki MT. Type 2 diabetes mellitus and its complications: from the molecular biology to the clinical practice. Rev Diabet Stud. 2004; 1: 5-8.

8. Peng HY, Zou LF, Xie JY, et al. IncRNA NONRATT021972 siRNA Decreases Diabetic Neuropathic Pain Mediated by the P2X3 Receptor in Dorsal Root Ganglia. Mol Neurobiol. 2017; 54: 511-23.

9. Whiting DR, Guariguata L, Weil C, et al. IDF diabetes atlas: global estimates of the prevalence of diabetes for 2011 and 2030. Diabetes Res Clin Pract. 2011; 94: $311-21$.

10. Cho NH, Shaw JE, Karuranga S, et al. IDF Diabetes Atlas: global estimates of diabetes prevalence for 2017 and projections for 2045. Diabetes Res Clin Pract. 2018; 138: 271-81.

11. Lutz SZ, Staiger H, Fritsche A, et al. Antihyperglycaemic therapies and cancer risk. Diab Vasc Dis Res. 2014; 11: 371-89.

12. Petersmann A, Nauck M, Müller-Wieland D, et al. Definition, Classification and Diagnosis of Diabetes Mellitus. Exp Clin Endocrinol Diabetes. 2018; 126: 406-10.

13. Wilson EB. A correlation curiosity. Science. 1932; 76: 515-6.

14. Ujpál M, Matos O, Bíbok G, et al. Stomato-oncological screening in diabetic patients. Fogorv Sz. 2003; 96:193-6.

15. Bronsveld HK, Jensen V, Vahl P, et al. Diabetes and Breast Cancer Subtypes. PLoS One. 2017; 12: e0170084.

16. Larsson SC, Orsini N, Wolk A. Diabetes mellitus and risk of colorectal cancer: a meta-analysis. J Natl Cancer Inst. 2005; 97:1679-87.

17. Friberg E, Orsini N, Mantzoros CS, et al. Diabetes mellitus and risk of endometrial cancer: a meta-analysis. Diabetologia. 2007; 50:1365-74.

18. El-Serag HB, Hampel H, Javadi F. The association between diabetes and hepatocellular carcinoma: a systematic review of epidemiologic evidence. Clin Gastroenterol Hepatol. 2006; 4:369-80.

19. Huxley R, Ansary-Moghaddam A, Berrington de González A, et al. Type-II diabetes and pancreatic cancer: a meta-analysis of 36 studies. Br J Cancer. 2005; 92: 2076-83.

20. Aleman JO, Eusebi LH, Ricciardiello L, et al. Mechanisms of obesity-induced gastrointestinal neoplasia. Gastroenterology. 2014; 146:357-73.

21. Bao B, Wang Z, Li Y, et al. The complexities of obesity and diabetes with the development and progression of pancreatic cancer. Biochim Biophys Acta. 2011; 1815:135-46.

22. Gristina V, Cupri MG, Torchio M, et al. Diabetes and cancer: A critical appraisal of the pathogenetic and therapeutic links. Biomed Rep. 2015; 3:131-6.

23. Goto A, Noto H, Noda M, et al. Report of the Japan diabetes society/Japanese cancer association joint committee on diabetes and cancer, Second report. Cancer Sci. 2016; 107:369-71.

24. Noto $\mathrm{H}$, Goto A, Tsujimoto $\mathrm{T}$, et al. Latest insights into the risk of cancer in diabetes. J Diabetes Investig. 2013; 4:225-32.

25. Maynard GD. A statistical study in cancer death-rates. Biome trika. 1909; 7: 276-304

26. Giovannucci E, Harlan DM, Archer MC, et al. Diabetes and cancer: a consensus report. CA Cancer J Clin. 2010; 60: 207-21.

27. Alenzi EO, Madhavan SS, Tan X. Association of the severity of diabetes-related complications with stage of breast cancer at diagnosis among elderly women with pre-existing diabetes. Breast Cancer Res Treat. 2018; 167: 183-93.

28. Weiderpass E, Gridley $G$, Nyren $O$, et al. Diabetes mellitus and risk of large bowel cancer. J Natl Cancer Inst. 1997; 89: 660-1.

29. Nilsen TI, Vatten LJ. Prospective study of colorectal cancer risk and physical activity, diabetes, blood glucose and BMI: exploring the hyperinsulinaemia hypothesis. Br J Cancer. 2001; 84: 417-22.

30. Hu FB, Manson JE, Liu S, et al. Prospective study of adult onset diabetes mellitus (type 2) and risk of colorectal cancer in women. J Natl Cancer Inst. 1999; 91: 542-7.

31. Gallagher EJ, Leroith D. Diabetes, cancer, and metformin: connections of metabolism and cell proliferation. Ann N Y Acad Sci. 2011; 1243: 54-68.

32. Tanaka T, Kawabata K, Sugie S. 4-Nitroquinoline 1-Oxide-Induced Tongue and Esophagus Carcinogenesis in Obese and Diabetic TSOD Mice. World J Oncol. 2017; 8:97-104.

33. Tseng KS, Lin C, Lin YS, et al. Risk of head and neck cancer in patients with diabetes mellitus: a retrospective cohort study in Taiwan. JAMA Otolaryngol Head Neck Surg. 2014; 140:746-53

34. Ujpál M, Matos O, Bíbok G, et al. Diabetes and oral tumors in Hungary: epidemiological correlations. Diabetes Care. 2004; 27: 770-4.

35. Wu CH, Wu TY, Li CC, et al. Impact of diabetes mellitus on the prognosis of patients with oral squamous cell carcinoma: a retrospective cohort study. Ann Surg Oncol. 2010; 17:2175-83.

36. Centers for Disease Control and Prevention. National Diabetes Statistics Report, 2017. Atlanta, GA: Centers for Disease Control and Prevention, U.S. Dept of Health and Human Services; 2017.

37. Bányai $\mathrm{D}$, Végh $\mathrm{D}$, Vaszilkó $\mathrm{M}$, et al. Incidence of type 2 diabetes among oral cancer patients in Hungary. Orv Hetil. 2018; 159:803-7.

38. Bao C, Pedersen NL, Yang R, et al. Diabetes in midlife and risk of cancer in late life: A nationwide Swedish twin study. Int J Cancer. 2018; 143:793-800.

39. $\mathrm{Li} \mathrm{H}$, Qian J. Association of diabetes mellitus with thyroid cancer risk: A meta-analysis of cohort studies. Medicine (Baltimore). 2017; 96: e8230. 
40. Chung-Ji Liu, Wan-Jung Chang, Chang-Yi Chen, et al. Dynamic cellular and molecular modulations of diabetes mediated head and neck carcinogenesis. Oncotarget. 2015; 6: 29268-84.

41. Ujpal M, Matos O, Bibok G, et al. Incidence of diabetes mellitus in patients with malignant tumors of the oral cavity. Orv Hetil. 2002; 143:2731-3.

42. Dikshit RP, Ramadas K, Hashibe M, et al. Association between diabetes mellitus and pre-malignant oral diseases: a cross sectional study in Kerala, India. Int. J. Cancer. 2006; 118: 453-7.

43. Petrou-Amerikanou C, Markopoulos AK, Belazi M, et al. Prevalence of oral lichen planus in diabetes mellitus according to the type of diabetes. Oral Dis. 1998; 4: 37-40.

44. Stott-Miller M, Chen C, Schwartz SM. Type II diabetes and metabolic syndrome in relation to head and neck squamous cell carcinoma risk: a SEER-Medicare database study. Cancer Epidemiol. 2013; 37:428-33.

45. Ankola AA, Smith RV, Burk RD, et al. Comorbidity, human papillomavirus infection and head and neck cancer survival in an ethnically diverse population. Oral Oncol. 2013; 49:911-7.

46. Nishimura G, Horiuchi C, Yoshida T, et al. Change of creatinine clearance rate in accordance with aging in Japanese patients with head and neck cancer. Gan To Kagaku Ryoho. 2006; 33: 463-6.

47. Tseng $\mathrm{CH}$. Pioglitazone and oral cancer risk in patients with type 2 diabetes. Oral Oncol. 2014; 50: 98-103.

48. Muoio DM, Newgard CB. Mechanisms of disease: Molecular and metabolic mechanisms of insulin resistance and beta-cell failure in type 2 diabetes. Nat Rev Mol Cell Biol. 2008; 9: 193-205.

49. Giovannucci E, Harlan DM, Archer MC, et al. Diabetes and cancer: a consensus report. Diabetes care. 2010; 33: 1674-85.

50. Yang H, Zhong JT, Zhou SH, et al. Adekola K, Rosen ST, Shanmugam M. Roles of GLUT-1 and HK-II expression in the biological behavior of head and neck cancer. Oncotarget. 2019; 10:3066-83.

51. Hua F, Yu J, Hu Z. Diabetes and cancer, common threads and missing links. Cancer Lett. 2016; 374: 54-61.

52. Ryu TY, Park J, Scherer PE. Hyperglycemia as a risk factor for cancer progression. Diabetes Metab J. 2014; 38: 330-6.

53. Weir GC, Bonner-Weir S. Five stages of evolving beta-cell dysfunction during progression to diabetes. Diabetes. 2004; 53:S16-21.

54. Dang CV. Links between metabolism and cancer. Genes Dev. 2012; 26: 877-90.

55. Alexander M, Krishnan B, Shenoy N. Diabetes mellitus and odontogenic infections an exaggerated risk? J Oral Maxillofac Surg. 2008; 12:129-30.

56. Ling Gao, Xiaolong Wang, Xiaofei Wang, et al. IGF-1R, a target of let-7b, mediates crosstalk between IRS-2/Akt and MAPK pathways to promote proliferation of oral squamous cell. Oncotarget. 2014; 5:2562-74.

57. Chen YC, Chen YW, Hsu HS, et al. Aldehyde dehydrogenase 1 is a putative marker for cancer stem cells in head and neck squamous cancer. Biochem Biophys Res Commun. 2009; 385: 307-13.

58. Park J, Morley TS, Kim M, et al. Obesity and cancer--mechanisms underlying tumour progression and recurrence. Nat Rev Endocrinol. 2014;10:455-65.

59. Hu Q, Peng J, Chen X, et al. Obesity and genes related to lipid metabolism predict poor survival in oral squamous cell carcinoma. Oral Oncol. 2019; 89: $14-22$

60. Viollet B, Guigas B, Garcia NS, et al. Cellular and molecular mechanisms of metformin: an overview. Clin Sci (Lond).. 2012; 122: 253-70.

61. Martin-Castillo B, Vazquez-Martin A. Metformin and cancer: doses, mechanisms and the dandelion and hormetic phenomena. Cell Cycle. 2010; 9: 1057-64.

62. Pisani P. Hyper-insulinaemia and cancer, meta-analyses of epidemiological studies. Arch Physiol Biochem. 2008; 114:63-70

63. Li D. Diabetes and pancreatic cancer. Mol Carcinog. 2012; 51: 64-74.

64. Renehan AG, Frystyk J, Flyvbjerg A. Obesity and cancer risk: the role of the insulin-IGF axis. Trends Endocrinol Metab. 2006; 17:328-36.

65. Papa V, Pezzino V, Costantino A, et al. Elevated insulin receptor content in human breast cancer. J Clin Invest. 1990; 86:1503-10.

66. Frasca F, Pandini G, Scalia P, et al. Insulin receptor isoform A, a newly recognized, high-affinity insulin-like growth factor II receptor in fetal and cancer cells. Mol Cell Biol, 1999, 19(5):3278-88.

67. Giovannucci E. Insulin, insulin-like growth factors and colon cancer: a review of the evidence. J Nutr. 2001; 131(11 Suppl):3109S-20S.

68. Weinstein D, Simon M, Yehezkel E, et al. Insulin analogues display IGF-I-like mitogenic and anti-apoptotic activities in cultured cancer cells. Diabetes Metab Res Rev. 2009; 25:41-9.

69. Pollak MN, Schernhammer ES, Hankinson SE. Insulin-Like Growth Factor System in Cancer: Novel Targeted Therapies. Biomed Res Int. 2015; 2015: 538019.

70. Kourelis TV, Siegel RD. Metformin and cancer: new applications for an old drug. Med Oncol. 2012; 29: 1314-27.

71. Belfiore A. The role of insulin receptor isoforms and hybrid insulin/IGF-I receptors in human cancer. Curr Pharm Des. 2007; 13: 671-86.

72. Stoeltzing $\mathrm{O}$, Liu $\mathrm{W}$, Reinmuth $\mathrm{N}$, et al. Regulation of hypoxia-inducible factor-1alpha, vascular endothelial growth factor, and angiogenesis by an insulin-like growth factor-I receptor autocrine loop in human pancreatic cancer. Am J Pathol. 2003; 163:1001-11.

73. Mardilovich K, Pankratz SL, Shawl M. Expression and function of the insulin receptor substrate proteins in cancer. Cell Commun Signal. 2009; 7:14.

74. Brahmkhatri VP, Prasanna C, Atreya HS. Insulin-like growth factor system in cancer: novel targeted therapies. Biomed Res Int. 2015; 2015: 538019.
75. Dehghan A, Kardysl, de Maat MP, et al. Genetic variation, C-reactive protein levels, and incidence of diabetes. Diabetes. 2007; 56:872-8.

76. Tanaka T, Shimizu M, Kochi T, et al. Apc-Mutant Kyoto Apc Delta(KAD) rats are susceptible to 4-NQO-Induced Tongue Carcinogenesis. Cancers (Basel). 2014; 6:1522-39.

77. Feller L, Khammissa RAG, Lemmer J. Biomechanical cell regulatory networks as complex adaptive systems in relation to cancer. Cancer Cell Int. 2017; 17:16.

78. Tanaka T. Colorectal carcinogenesis: Review of human and experimental animal studies. J Carcinog. 2009; 8: 5.

79. Hanahan D, Weinberg RA. Hallmarks of cancer: the next generation. Cell. 2011; 144:646-74.

80. Komura T, Sakai Y, Honda M, et al. CD14+ monocytes are vulnerable and functionally impaired under endoplasmic reticulum stress in patients with type 2 diabetes. Diabetes. 2010; 59:634-43.

81. Sgambato A, Cittadini A. Inflammation and cancer: a multifaceted link. Eur Rev Med Pharmacol Sci. 2010; 14:263-8.

82. Skamagas M, Breen TL, LeRoith D. Update on diabetes mellitus: prevention, treatment, and association with oral diseases. Oral Dis. 2008; 14:105-14.

83. Cakir E. Is there any relationship between recurrent oral aphthous stomatitis and prediabetes?. Med Hypotheses. 2013; 81:512-3.

84. Micucci C, Valli D, Matacchione G, et al. Current perspectives between metabolic syndrome and cancer. Oncotarget. 2016; 7: 38959-72

85. Kong $\mathrm{P}, \mathrm{Wu} \mathrm{R}, \mathrm{Liu} \mathrm{X}$, et al. The effects of anti-inflammatory drug treatment in gastric cancer prevention: an update of a meta-analysis. J Cancer. 2016; 7: 2247-57.

86. Skriver C, Dehlendorff C, Borre M, et al. Low-dose aspirin or other nonsteroidal anti-inflammatory drug use and prostate cancer risk: a nationwide study. Cancer Causes Control. 2016; 27: 1067-79.

87. Friis S, Riis AH, Erichsen R, et al. Low-dose aspirin or nonsteroidal anti-inflammatory drug use and colorectal cancer risk: a population-based, case-control study. Ann Intern Med. 2015; 163: 347-55.

88. Hoesel B, Schmid JA. The complexity of NF-kappaB signaling in inflammation and cancer. Mol Cancer. 2013; 12: 86

89. Barone BB, Yeh HC, Snyder CF, et al. Long-term all-cause mortality in cancer patients with preexisting diabetes mellitus: a systematic review and meta-analysis. JAMA. 2008; 300: 2754-64.

90. Vairaktaris E, Spyridonidou S, Goutzanis L, et al. Diabetes and oral oncogenesis. Anticancer Res. 2007; 27: 4185-93.

91. Ang KK, Harris J, Wheeler R, et al. Human papillomavirus and survival of patients with oropharyngeal cancer. New England J Med. 2010; 363: 24-35.

92. Gillison ML, Koch WM, Capone RB, et al. Evidence for a Causal Association Between Human Papillomavirus and a Subset of Head and Neck Cancers. J National Cancer Inst. 2000; 92:709-20.

93. Mclaughlindrubin ME, Münger K. The human papillomavirus E7 oncoprotein. Virology. 2009; 384:335-44.

94. Chen SF, Yu FS, Chang YC, et al. Role of human papillomavirus infection in carcinogenesis of oral squamous cell carcinoma with evidences of prognostic association. J Oral Pathol Med. 2012; 41:9-15.

95. Surviladze Z, Sterk RT, Deharo SA, et al. Cellular entry of human papillomavirus type 16 involves activation of the phosphatidylinositol 3-kinase/Akt/mTOR pathway and inhibition of autophagy. J Virol. 2013; 87:2508-17.

96. Fisichella L, Fenga D, Rosa MA. Surgical site infection in orthopaedic surgery: correlation between age, diabetes, smoke and surgical risk. Folia Med (Plovdiv). 2014; 56:259-63.

97. Dwyer CJ, Ward NC, Pugliese A, et al. Promoting immune regulation in type 1 diabetes using low-dose interleukin-2. Curr Diab Rep. 2016; 16:46.

98. Chen $\mathrm{YH}$, Lee $\mathrm{CH}, \mathrm{Hsu} \mathrm{TH}$, et al. Submerged culture mycelia and broth of the maitake medicinal mushroom grifola frondosa (higher basidiomycetes) alleviate type 2 diabetes induced alterations in immunocytic function. Int J Med Mushrooms. 2015; 17:541-56.

99. Naruishi $\mathrm{K}$, Omori $\mathrm{K}$, Maeda $\mathrm{H}$, et al. Immune responses to porphyromonas gingivalis infection suppress systemic inflammatory response in experimental murine model. J Biol Regul Homeost Agents. 2011; 25:195-202.

100. Li Y, Zhou $\mathrm{L}$, Li Y, et al. Identification of autoreactive CD8+T cell responses targeting chromogranin a in humanized NOD mice and type 1 diabetes patients. Clin Immunol. 2015; 159: 63-71.

101. Chow IT, Yang J, Gates TJ, et al. Assessment of CD4+ T cell responses to glutamic acid decarboxylase 65 using DQ8 tetramers reveals a pathogenic role of GAD65 121-140 and GAD65 250-266 in T1D development. PLoS One. 2014; 9:e112882.

102. Kalantar F, Dabbaghmanesh $\mathrm{MH}$, Martinuzzi $\mathrm{E}$, et al. Islet amyloid polypeptide is not a target antigen for $\mathrm{CD} 8+\mathrm{T}$-cells in type 2 diabetes. Iran $\mathrm{J}$ Immunol. 2014; 11: 1-12.

103. Lei L, Mao Y, Meng D, et al. Percentage of circulating CD8+T lymphocytes is associated with albuminuria in type 2 diabetes mellitus. Exp Clin Endocrinol Diabetes. 2014; 122:27-30

104. Shaw R J, Lamia K A, Vasquez D, et al. The kinase LKB1 mediates glucose homeostasis in liver and therapeutic effects of metformin. Science. 2005; 310: $1642-6$.

105. Sui $X, X u$ Y, Wang $X$, et al. Metformin: a novel but controversial drug in cancer prevention and treatment. Mol Pharm. 2015; 12: 3783-91.

106. Association AD. Standards of medical care in diabetes- 2015 abridged for primary care providers. Clin Diabetes. 2015; 33: 97-111. 
107. Klubo-Gwiezdzinska J, Jensen K, Costello J, et al. Metformin inhibits growth and decreases resistance to anoikis in medullary thyroid cancer cells. Relat Cancer. 2012; 19: 447-56.

108. Tseng $\mathrm{CH}$. Metformin and esophageal cancer risk in Taiwanese patients with type 2 diabetes mellitus. Oncotarget. 2017; 8:18802-10.

109. Zhu N, Zhang Y, Gong Y I, et al. Metformin and lung cancer risk of patients with type 2 diabetes mellitus: a meta-analysis. Biomed Rep. 2015; 3: 235-41.

110. Ma S J, Zheng YX, Zhou P C, et al. Metformin use improves survival of diabetic liver cancer patients: systematic review and meta-analysis. Oncotarget. 2015; 7: 66202-11.

111. Kato K, Gong J, Iwama H, et al. The antidiabetic drug metformin inhibits gastric cancer cell proliferation in vitro and in vivo. Mol Cancer Ther. 2012; 11: $549-60$.

112. Greenhill C. Gastric cancer: Metformin improves survival and recurrence rate in patients with diabetes and gastric cancer. Nat Rev Gastroenterol Hepatol. 2015; 12: 124.

113. Bao B, Wang Z, Ali S, et al. Metformin inhibits cell proliferation, migration and invasion by attenuating CSC function mediated by deregulating miRNAs in pancreatic cancer cells. Cancer Prev Res (Phila). 2012; 5: 355-64.

114. Wang Z, Lai S T, Xie L, et al. Metformin is associated with reduced risk of pancreatic cancer in patients with type 2 diabetes mellitus: a systematic review and meta-analysis. Diabetes Res Clin Pract. 2014; 106: 19-26.

115. Liu F, Yan L, Wang Z, et al. Metformin therapy and risk of colorectal adenomas and colorectal cancer in type 2 diabetes mellitus patients: a systematic review and meta-analysis. Oncotarget. 2017; 8:16017-26.

116. Zhang J, Shen C, Wang L, et al. Metformin inhibits epithelial-mesenchymal transition in prostate cancer cells: involvement of the tumor suppressor miR30a and its target gene SOX4. Biochem Biophys Res Commun. 2014; 452: $746-52$.

117. Stopsack KH, Ziehr DR, Rider JR, et al. Metformin and prostate cancer mortality: a meta-analysis. Cancer Causes Control. 2016; 27: 105-13.

118. Dilokthornsakul P, Chaiyakunapruk N, Termrungruanglert W, et al. The effects of metformin on ovarian cancer: a systematic review. Int J Gynecol Cancer. 2013; 23: 1544-51.

119. Tan BK, Adya R, Chen J, et al. Metformin treatment exerts antiinvasive and antimetastatic effects in human endometrial carcinoma cells. J Clin Endocrinol Metab. 2011; 96: 808-16.

120. Kusturica J, Kulo Cesic A, Gusic E, et al. Metformin use associated with lower risk of cancer in patients with diabetes mellitus type 2. Med Glas (Zenica). 2017; 14: 176-81.

121. Rêgo DF, Pavan L MC, Elias ST, et al. Effects of metformin on head and neck cancer: a systematic review. Oral Oncol. 2015; 51: 416-22.

122. Skinner HD, Sandulache VC, Ow TJ, et al. TP53 disruptive mutations lead to head and neck cancer treatment failure through inhibition of radiation-induced senescence. Clin Cancer Res. 2012; 18: 290-300.

123. Yen YC, Lin C, Lin SW, et al. Effect of metformin on the incidence of head and neck cancer in diabetics. Head Neck. 2014; 37: 1268-73.

124. Becker C, Jick SS, Meier CR, et al. Metformin and the risk of head and neck cancer: a case-control analysis. Diabetes Obes Metab. 2014; 16: 1148-54.

125. Kwon M, Roh JL, Song J, et al. Effect of metformin on progression of head and neck cancers, occurrence of second primary cancers, and cause-specific survival. Oncologist. 2015; 20: 535-45.

126. Figueiredo RA, Weiderpass E, Tajara EH, et al. Diabetes mellitus, metformin and head and neck cancer. Oral Oncol. 2016; 61: 47-54.

127. Vitale CL, Molinolo AA, Martin D, et al. Metformin prevents the development of oral squamous cell carcinomas from carcinogen -induced premalignant lesions. Cancer Prev Res (Phila). 2012; 5: 562-73.

128. Patel H, Younis RH, Ord RA, et al. Differential expression of organic cation transporter OCT-3 in oral premalignant and malignant lesions: potential implications in the antineoplastic effects of metformin. J Oral Pathol Med. 2013; 42: 250-6.

129. Madera D, Vitalecross L, Martin D, et al. Prevention of tumor growth driven by PIK3CA and HPV oncogenes by targeting $m$ TOR signaling with metformin in oral squamous carcinomas expressing OCT3. Cancer Prev Res. 2015; 8: 197-207.

130. Stokes WA, Eguchi M, Amini A, et al. Survival impact and toxicity of metformin in head and neck cancer: An analysis of the SEER-Medicare dataset. Oral Oncol. 2018; 84: 12-9.

131. Wu P, Tang Y, Fang X, et al. Metformin Suppresses Hypopharyngeal Cancer Growth by Epigenetically Silencing Long Non-coding RNA SNHG7 in FaDu Cells. Front Pharmacol. 2019; 10:143.

132. Kuo SZ, Honda CO, Li WT, et al. Metformin Results in Diametrically Opposed Effects by Targeting Non-Stem Cancer Cells but Protecting Cancer Stem Cells in Head and Neck Squamous Cell Carcinoma. Int J Mol Sci. 2019; 20:193.

133. Hsieh MC, Lee TC, Cheng SM, et al. The influence of type 2 diabetes and glucose- lowering therapies on cancer risk in the Taiwanese. Exp Diabetes Res. 2012; 2012: 413782

134. Thakkar B, Aronis KN, Vamvini MT, et al. Metformin and sulfonylureas in relation to cancer risk in type II diabetes patients: a meta-analysis using primary data of published studies. Metabolism. 2013; 62: 922-34.

135. Elashoff M, Matveyenko AV, Gier B, et al. Pancreatitis, pancreatic, and thyroid cancer with glucagon-like peptide-1-based therapies. Gastroenterology. 2011; 141: $150-6$

136. Pollak MN. Investigating metformin for cancer prevention and treatment: the end of the beginning. Cancer Discov. 2012; 2: 778-90.
137. Sabatini DM. mTOR and cancer: insights into a complex relationship. Nat Rev Cancer. 2006; 6: 729-34.

138. Inoki K, Zhu T, Guan K L. TSC2 mediates cellular energy response to control cell growth and survival. Cell. 2003; 115: 577-90.

139. Alessi D R, Sakamoto K, Bayascas JR. LKB1-dependent signaling pathways. Annu Rev Biochem. 2006; 75: 137-63.

140. Rosta A. Diabetes and cancer risk: oncologic considerations. Orvosi Hetilap. 2011; 152: 1144-55.

141. Rattan R, Ali FR, Munkarah A. Metformin: an emerging new therapeutic option for targeting cancer stem cells and metastasis. J Oncol. 2012; 2012: 928127.

142. Rêgo DF, Elias S, Amato A L, et al. Anti-tumor effects of metformin on head and neck carcinoma cell lines: a systematic review. Oncol Lett. 2016; 13: 554-66.

143. Hirsch HA, Iliopoulos D, Struhl K. Metformin inhibits the inflammatory response associated with cellular transformation and cancer stem cell growth. Proc Natl Acad Sci USA. 2013; 110: 972-7.

144. Tadakawa M, Takeda $\mathrm{T}$, Li B, et al. The anti-diabetic drug metformin inhibits vascular endothelial growth factor expression via the mammalian target of rapamycin complex 1 /hypoxia-inducible factor-1a signaling pathway in ELT-3 cells. Mol Cell Endocrinol. 2014; 399: 1-8.

145. Alberti KG, Zimmet P. Global burden of disease--where does diabetes mellitus fit in? Nat Rev Endocrinol. 2013; 9: 258-60. 